\title{
36. NUEVOS DATOS PARA LA PTERIDOFLORA DE LOS PORTS DE BESEIT (S. DE CATALUÑA Y N. DEL PAÍS VALENCIANO)
}

\author{
Lorenzo SÁEZ y Josep Manuel ÁLVAREZ
}

Palabras clave. Pteridófitos, corología, Sistema Ibérico, España.

Como resultado de las recolecciones realizadas en el macizo de los Ports de Beseit, damos cuenta de la presencia de tres pteridófitos (Asplenium adiantum-nigrum L. var. adiantum-nigrum, Asplenium seelosii Leybold subsp. celtibericum (Rivas-Martínez) P. Monts. y Polystichum setiferum (Forsskål) Woynar) que no se incluyen en el catálogo florístico de estas montañas (Ll. de Torres, Flora del massis del Port. Publicacions de la Diputació de Tarragona. 1989); asimismo el segundo de ellos supone novedad para la flora de Cataluña.

Los datos correspondientes a cada taxon son los siguientes:

Asplenium adiantum-nigrum L. var. adiantumnigrum

CASTELLÓN: El Boixar, Barranc de la Canal, 31T BF 5507, 1080 m, 28-V-92, J.M. Álvarez (BCC).

Recolectado en un talud margoso húmedo asentado sobre dolomías del Cretácico inferior, el cual se halla en contacto con un avellanar (SaniculoTaxetum O. Bolòs 1967) orientado al norte.

Las localidades más cercanas de donde se conoce este taxon son: CASTELLÓN: Penyagolosa 30T YK 26, Mas de Navarro, 1450 m (J. Vigo, La vegetació del massis de Penyagolosa, Inst. Est. Cat., secc. Ciènc. Barcelona. 37: 37. 1968). TARRAGONA: Montes de Prades, Tossal de la Baltasana, 31T CF 37 (F. Masclans \& E. Batalla, Collect. Bot. 6: 495. 1964).

Asplenium seelosii Leybold subsp. celtibericum (Rivas-Martínez) P. Monts.

(= A. celtibericum Rivas-Martínez)

TARRAGONA: Ports de Beseit, El Retaule, $31 \mathrm{~T}$ BF 61, 1090 m, VI-89, J.M. Álvarez, A.
Carrillo, L. Sáez y J. Vicens, det. P. Cubas, (MAF).

Asplenium seelosii subsp. celtibericum presenta un área de distribución que se extiende por las zonas montañosas calcáreas de la mitad oriental de la Península Ibérica. Hasta el momento se desconocía la presencia de esta taxon en Cataluña, no así la de Asplenium seelosii Leybold subsp.catalaunicum (O. Bolòs \& Vigo) P. Monts. (=A. seelosii Leybold subsp. glabrum (Litard. \& Maire) Rothm. var. catalaunicum $\mathrm{O}$. Bolòs \& Vigo), del cual se conocen diversas localidades, todas ellas del Pirineo calcáreo catalán.

La nueva población de la cual damos cuenta, que representa el límite oriental del área de distribución de Asplenium seelosii subsp. celtibericum, se localiza en los extraplomos constituidos por dolomías masivas grises del Lías, situados en la vertiente oeste de la zona del Retaule. En este lugar se han localizado unos pocos ejemplares, los cuales forman parte de la comunidad Antirrhinetum pertegasii O. Bolòs 1967.

La morfología de la fronde (limbo subentero, ovado-lanceolado, irregularmente inciso-dentado y glabro), la distancia entre esta localidad y las poblaciones pirenaicas así como su proximidad con las ibéricas (30T XK 97, Sierra de Gúdar, bajo el Collado de la Gitana; Borja, Mansanet y RivasMartínez, Bull. Jard. Bot. Nat. Belg. 37: 330. 1967) hacen pensar que la planta recolectada en los Ports de Beseit debe adscribirse a Asplenium seelosii subsp. celtibericum.

\section{Polystichum setiferum (Forsskål) Woynar}

TARRAGONA: Ports de Beseit.

Cerca de Horta, 31T BF 72, 1100 m, 27-VII90, J. Molero (BCF), sub. P. aculeatum (L.) Roth. Cercanías del Salt del Ximenot, 31T BF 7623, $850 \mathrm{~m}, 18-\mathrm{XI}-90$. Taludes húmedos en el margen de un encinar. L. Sáez (herb. pers.). 
Carrer Ample, 31T BF 7527, 670 m, 6-II-92. Mosqueruela, 30T YK 26, 1000 m, G. Mateo, Entre bloques de calizas bioclásticas liásicas. L. (VAB 85794).

Sáez (herb. pers.).

Estas localidades contribuyen a ampliar el área de distribución de esta especie en la provincia de Tarragona, de donde era conocida únicamente su presencia en el Coll de la Teixeta (31T CF 25, 580 m, R. Folch \& M. Brugués, BC 627982).

En el Sistema Ibérico, la localidad más cercana es la siguiente: CASTELLÓN: Vistabella hacia Aceptado para su publicación en Marzo de 1993

Dirección de los autores. L. SÁEZ: C/Pare Francesc Molina, 14. 07003, Palma de Mallorca. J.M. ÁLVAREZ: Dpto. Biología Vegetal. Facultad de Biología, Universidad de Barcelona. 08028, Barcelona. 